\title{
Risk Factors for Low Birth Weight Babies in Hail Region KSA
}

\author{
Rania Abdeen ${ }^{1}$, Aljohrah Albaker ${ }^{2}$, Amal Al-Buqaisi ${ }^{3}$, Hala Alassaf $^{4}$, Latifah Alateeq $^{5}$, \\ Wasmiah Alshammri ${ }^{6}$ \\ ${ }^{1}$ University of Hail Faculty of Medicine Department of Obstetrics and Gynecology KSA \\ $2,3,4,5,6$ University of Hail Faculty of Medicine $4^{\text {th }}$ year Medical Students KSA
}

\begin{abstract}
Introduction: Low birth weight (LBW) means that the weight at birth is <2500]. LBW has significant role in neonatal mortality and morbidity [12]. Generally its known that the causes of LBW is multi factorial. Regarding KSA the incidence was found 7.4. Objective: Of our study to find out risk factors associated with delivering LBW babies in Hail region KSA like (Maternal age, Education, occupation, monthly income, ANC, Supplementation, maternal smoking, Gestational age, Babies gender, birth order, Previous recurrent miscarriage and Previous history of $L B W$ baby). Methodology: the design is case control study; cases are women who delivered babies weigh $<2500 \mathrm{~g}$ while control are women who delivered baby weight $\geq 2500 \mathrm{~g}$. Our data were collected from two hospitals in Hail; maternity and general hospital through structured questionnaire. We collect data from 500 delivered women (200 cases, $300 c o n t r o l)$ during the period from October to December 2015.Analyses Using SPSS, P-value was taken. Results: Out of 15 possible risk variables analyzed, 3 were found significant. Baby gender $(P<0.05)$, gestational age $(P=<0.05)$, and passive smoking $(P=<0.05) . \underline{\text { Conclusion: }}$ passive smoking, gestational age, and baby's gender had significant effect on LBW babies
\end{abstract}

Keywords: LBW: low birth Weight, VLBW: very low birth Weight, IUGR: intrauterine growth Restriction, ANC: antenatal care and BW: birth weight.

\section{Introduction}

LBW means birth weight is $<2500 \mathrm{~g}$ [1], [2]. When the weight is $<1500 \mathrm{~g}$ we defined as VLBW and this associated with about $50 \%$ of the neonatal deaths [3]. During the last two decade the incidence of LBW had increase because of an increase No of preterm's [3].

LBW is a global health problem with different geographic distribution. Latest estimates suggest that LBW babies constitute about $16 \%$ of all live births, with $19 \%$ occurring in the least developed and developing nations and $7 \%$ in the developed countries [4]. According to WHO report $11 \%$ of infant have LBW in the middle east [5].Regarding KSA in one study in Riyadh (1987-1988) the incidence was found $8.4 \%$ and when stillbirth excluded it became $7.4[6]$, this is in agreement with $2^{\text {nd }}$ study in Riyadh (1992-1995) [7].

LBW has significant role in neonatal mortality and morbidity [8]. LBW babies have increase risk of developing neuro-developmental disorders and learning disabilities compared to the normal children [5]. The long hospital stay and treatment of complication will have more financial cost on health services [9]. Also during childhood medical condition like asthma, ear infection and upper and lower respiratory are more common in LBW babies [10].

Usually LBW is caused by either prematurity or (IUGR) [11] prematurity is defined as delivery of the baby between $24+0$ and $36+6$ weeks of gestation. While IUGR is define as failure of the fetus to reach its genetic growth potentials, this usually result in reduced the weight of the fetus [12].

Generally it is known that the causes of LBW is multi factorial [8], some of these factors can be prevented like alcohol, smoking or drug use during pregnancy [13].

\section{Literature Review}

Maternal age in one study was found to be significant risk factors of LBW especially for women who were older than 35 years $(\mathrm{P}<0.004)[14]$.

Maternal education has been taken as one of the risks factors for LBW, the women who had bachelor degree or higher education the percentage of LBW was $43.3 \%$. [15]. conversely other study in Bangladesh showed that the women who had primary or secondary education the percentage of $\mathrm{LBW}$ was $30.5 \%$ and for the women who had a collage degree or above the percentage of LBW was $8.3 \%$ $(\mathrm{P}<0.001)[16]$

Other factor like mother occupation had been studied, the type of work and the standing and sitting hours may affect, and this in harmony with study which was performed by Johns Hopkins University showed that the LBW rate was higher among the standing group 5.5\% compared with those in the sedentary jobs $4 \%$ and active groups $4 \%$, but this association was not significant when confounding factors were controlled [17]. Another study revealed that the Housewife women had $80.5 \%$ of LBW and for working women the LBW percentage $19.5 \%(\mathrm{P}<0.01)$ [16].

Antenatal care is found to be one of the factors associated with LBW as the more visits the more heath education, the more screening for complication and the more supplement given. In Oman there was study which found that $15.1 \%$ of women who had less than 4 ANC visits have LBW infant and $84.9 \%$ of women who had more or equal than 4 ANC visits have LBW infant [18]. Conversely another study found out that women who had poor quality antenatal care the percentage of LBW was $39.8 \%$ and women who had 


\section{International Journal of Science and Research (IJSR) \\ ISSN (Online): 2319-7064 \\ Index Copernicus Value (2013): 6.14 | Impact Factor (2015): 6.391}

average quality antenatal care the percentage of $\mathrm{LBW}$ was $60.1 \%(\mathrm{P}<0.001)[16]$

According to the study of quality of antenatal care and its dose-response relationship with birth weight in a maternal and child health, the mean birth weight of the babies increased with an increase in quality of antenatal care, the babies of the mothers who had $6+$ antenatal visits were found to be $727.26 \mathrm{~g}$ heavier than those who had 1-3 visits and $325.88 \mathrm{~g}$ heavier than those who had 4-5 visits [19].

The effect of use of supplementation during pregnancy like folic acid, iron and calcium is studied in many researches. Folic acid had role in prevention of neural tube defect if taken during the first trimester of pregnancy [20, 21], as these congenital anomalies will lead to IUGR and so LBW [12]. One study about the use of Multivitamin/Mineral Prenatal Supplements and the outcome of pregnancy showed that usage of prenatal supplement the 1ST or the 2ND trimester was associated with a diminished risk of VLBW infants [22]. In rural Gambia there was study done about effects of maternal dietary supplements on birth weight and prenatal mortality found out that the use of prenatal supplements significantly increased birth weight, particularly during the nutritionally debilitating hungry season (June to October) [23].

Cigarettes smoking had an important effect on the fetus, as smoking will reduced placental perfusion leading to IUGR [12]. Number of studies has found that prenatal smoking is associated with a reduction of birth weight of offspring by 150-250 grams (g) [24]. Other researches has related smoking during pregnancy to other problems such as low birth weight, preterm birth, intrauterine growth retardation, placental abruption, and sudden infant death syndrome [25].

We had one study done on Arab women in Qatar and it showed that a larger proportion of mothers who gave birth to an LBW child were cigarettes smoker $(5.3 \%$ cases vs. $3.8 \%$ controls $)(\mathrm{p}<0.164)[26]$. Similarly another study done in Iraqi, 150 women not exposed to passive smoking at home and 150 women exposed to passive smoking. Exposed women had a 3.07 higher risk of having LBW baby $(\mathrm{P}<$ 0.05).The mean birth weight of the passive smoke-exposed babies was significantly lower than that of the non-exposed babies $(\mathrm{P}<0.001)[27]$.

History of recurrent miscarriage and Previous history of LBW may be one of the factors associated with LBW.As there are common factors which can lead to the miscarriage as well as LBW like anti-phospholipids syndrome [22],similar result was found in study done in Bangladesh, which found that the women who had not experienced any previous miscarriages the percentage of LBW was $35.1 \%$ and the women who had a previous miscarriages the percentage of LBW was $5.5 \%$ the relation between abortion and LBW is statistically insignificant [16].

Two studies in Nigeria and Jordan found that women who had a previous LBW baby, she has significantly higher risk of another LBW baby $(28,29)$.
Monthly income as one of the predictor of social class can affect the birth weight as low income associated with poor nutrition and may be even male nutrition which may lead to LBW. We had one study which found that women who had Yearly income Below average per person the percentage of LBW was $85.1 \%$, while women who had yearly income above average per person the percentage of LBW was $14.8 \%(\mathrm{p}<0.001)$ [20].Sex of the baby may had relation with LBW as male babies are heavier than female. One study found that the male babies 1 st born term of mothers were found to be $45 \mathrm{~g}$ heavier than female babies. Also in preterm babies, the males outweighed the female babies by $111 \mathrm{~g}$, the mean birth weights were $2089 \mathrm{~g}$ and $1978 \mathrm{~g}$ respectively $(\mathrm{P}<0.001)[30]$.

\section{Study Objective}

To determine the association between LBW and maternal age, education level of the mother, mother's occupation, ANC visits, usage of prenatal supplements, active and passive smoking, previous history of recurrent miscarriage, family income, gestational age, order of the baby, gender of the baby and previous LBW baby.

\section{Material and Method}

Our study was conducted in Hail city KSA. It is big city situated in the north of KSA.

We collect our data from tow hospitals; the first one is maternity hospital which is biggest referral hospital for all Hail region, the second one is Hail general hospital which is smaller than maternity hospital.

Our study design was cross sectional study, cases are Saudi women who delivered babies weigh $<2500 \mathrm{~g}$ while control are Saudi women who delivered baby weight $\geq 2500$ g.we exclude from study any women with any medical disease, any women who delivered babies with obvious congenital malformations or Fetal death also any women who delivered multiple babies like twin's babies.

Our sample size was Control 300 women Case 200 We collect data through personal interviews using a structured questionnaire during the period from October to December 2015, a research approval was obtained from the Dean of the College of Medicine at the University of Hail, full explanation of the study was provided with the questionnaires given to each participant prior to their recruitment, explaining the purpose of this study.

The data were revised, coded and analyzed using SPSS, version 16. Descriptive statistics were computed for all variables. Chi-squared were used to test the differences between maternal characteristics among LBW and NBW for categorical variables. $\mathrm{P}<0.05$ was considered as statistically significant.

\section{Results}

Our result showed that the common age group was 20-29 years, $(65 \%$, and $57.67 \%)$ in cases and controls respectively. And we found that there were no statistically significant 


\section{International Journal of Science and Research (IJSR) \\ ISSN (Online): 2319-7064 \\ Index Copernicus Value (2013): 6.14 | Impact Factor (2015): 6.391}

differences in both groups in term of maternal age group (Pvalue>0.05).Regarding the comparison between the LBW and NBW in the term of maternal education, occupation and monthly income the results showed that there were also no significant differences $(\mathrm{P}=>0.05),(\mathrm{P}=>0.05),(\mathrm{p}=>0.05)$ respectively as showed in (table 4.1 )

Regarding antenatal care almost all mothers in both case and control groups had regular ANC visits and there was no significant association $(\mathrm{P}=>0.05)$. Also there was no significant association between LBW and supplementation usage during pregnancy $(\mathrm{P}=>0.05)$ as shown in (table 4.2)

Regarding active and passive smoking women. We compare between LBW and NBW infants in terms of maternal active and passive smoking.
For active smoking: there was no significant differences in both groups (P-value>0.05) whereas in passive smoking (Second Hand Smoking): there was a significant differences in both groups (P-value< 0.05$)$ as shown in (table 4.3$)$.

Regarding comparison between LBW and NBW infants in terms of gestational age, baby gender, birth order, previous history of abortion and previous history of LBW baby.

There was significant association in the gestational age and baby gender in both groups $(\mathrm{P}<0.05)(\mathrm{P}<0.05)$ respectively. We found that there were no significant differences in birth order, Previous history of abortion and previous history of LBW baby in both groups $(\mathrm{P}>0.05)(\mathrm{P}>0.05)(\mathrm{P}>0.05)$. As shown in (table 4.4)

Table 4.1

Table 4.1 shows the effects of Maternal age, Education, Occupation and Monthly income on Infant BW.

\begin{tabular}{|c|c|c|c|c|c|c|}
\hline \multirow[t]{2}{*}{ Maternal characteristics } & \multicolumn{4}{|c|}{$\begin{array}{l}\text { Infant birth weight group } \\
L B W(200) N B W(300)\end{array}$} & \multirow[t]{2}{*}{ Chi-square } & \multirow[t]{2}{*}{$P$-value } \\
\hline & no & $\%$ & no & $\%$ & & \\
\hline $\begin{array}{l}\text { Maternal age } \\
<20 \\
20-29 \\
30-39 \\
>40\end{array}$ & $\begin{array}{l}-2 \\
4 \\
130 \\
62 \\
4\end{array}$ & $\begin{array}{l}2 \% \\
65 \% \\
31 \% \\
2 \%\end{array}$ & \begin{tabular}{|l|} 
\\
9 \\
173 \\
102 \\
16 \\
\end{tabular} & $\begin{array}{l}3 \% \\
57.67 \% \\
34 \% \\
5.33 \%\end{array}$ & 5.189 & 0.158 \\
\hline $\begin{array}{l}\text { Education } \\
\text { Illiterates } \\
\text { Primary-intermediate-secondary school } \\
\text { University or higher }\end{array}$ & $\begin{array}{l}11 \\
75 \\
114\end{array}$ & $\begin{array}{l}5.5 \% \\
37.5 \% \\
57 \%\end{array}$ & $\begin{array}{l}6 \\
99 \\
195 \\
\end{array}$ & $\begin{array}{l}2 \% \\
33 \% \\
65 \%\end{array}$ & 5.876 & 0.053 \\
\hline $\begin{array}{l}\text { Occupation } \\
\text { No } \\
\text { Yes } \\
\end{array}$ & $\begin{array}{l}102 \\
98\end{array}$ & $\begin{array}{l}51 \% \\
49 \% \\
\end{array}$ & $\begin{array}{l}177 \\
123 \\
\end{array}$ & $\begin{array}{l}59 \% \\
41 \% \\
\end{array}$ & 2.612 & 0.106 \\
\hline $\begin{array}{l}\text { Monthly income } \\
<3600 \text { SR } \\
3600-13000 \text { SR } \\
>13000 \text { SR }\end{array}$ & $\begin{array}{l}103 \\
58 \\
39\end{array}$ & $\begin{array}{l}51.5 \% \\
29 \% \\
19.5 \%\end{array}$ & $\begin{array}{l}147 \\
74 \\
79\end{array}$ & \begin{tabular}{|l|}
$49 \%$ \\
$24.67 \%$ \\
$26.33 \%$
\end{tabular} & 3.925 & 0.141 \\
\hline
\end{tabular}

Table 4.2

Table 4.2 shows the effects of ANC visits and

Supplementation usage on Infant BW.

\begin{tabular}{|c|c|c|c|c|c|c|}
\hline \multirow{2}{*}{ Maternal characteristics $I$} & \multicolumn{4}{|c|}{$\begin{array}{l}\text { Infant birth weight group } \\
L B W(200) N B W(300)\end{array}$} & \multirow{2}{*}{$\begin{array}{c}\text { Chi- } \\
\text { square }\end{array}$} & \multirow{2}{*}{$\begin{array}{c}P- \\
\text { value }\end{array}$} \\
\hline & no & $\%$ & no & $\%$ & & \\
\hline $\begin{array}{l}\text { ANC visits } \\
\geq 4 \text { regular } \\
<4 \text { irregular } \\
\text { Never } \\
\end{array}$ & \begin{tabular}{|l}
172 \\
25 \\
3 \\
\end{tabular} & $\begin{array}{l}86 \% \\
12.5 \% \\
1.5 \% \\
\end{array}$ & $\begin{array}{l}243 \\
50 \\
7 \\
\end{array}$ & $\begin{array}{l}81 \% \\
16.67 \% \\
2.33 \% \\
\end{array}$ & 2.167 & 0.338 \\
\hline $\begin{array}{l}\text { upplementation usage } \\
\text { egular } \\
\text { rregular } \\
\text { Jever }\end{array}$ & $\begin{array}{l}133 \\
53 \\
14\end{array}$ & $\begin{array}{l}66.5 \% \\
26.5 \% \\
7 \%\end{array}$ & $\begin{array}{l}210 \\
79 \\
11\end{array}$ & $\begin{array}{l}70 \% \\
26.33 \% \\
3.67 \%\end{array}$ & 2.882 & 0.237 \\
\hline
\end{tabular}

Table4.3

Table 4.3 shows the effects of Active smoking and Passive smoking on Infant BW.

\begin{tabular}{|l|c|c|c|c|c|c|}
\hline \multirow{3}{*}{$\begin{array}{c}\text { Maternal } \\
\text { characteristics }\end{array}$} & \multicolumn{2}{|c|}{ Infant birth weight group } & $\begin{array}{c}\text { Chi- } \\
\text { LBW } 200)\end{array}$ & $\begin{array}{c}P \text { - } \\
\text { value }\end{array}$ \\
\cline { 2 - 6 } & no & $\%$ & no & $\%$ & & \\
\hline $\begin{array}{l}\text { Active smoking } \\
\text { Yes } \\
\text { No }\end{array}$ & 4 & $2 \%$ & 3 & $1 \%$ & 1.799 & 0.180 \\
\hline $\begin{array}{l}\text { Passive smoking * } \\
\text { Yes } \\
\text { No }\end{array}$ & 196 & $98 \%$ & 297 & $99 \%$ & & \\
\hline
\end{tabular}

$*(\mathrm{P}$-value $<0.05)$

\section{Table4.4}

Table 4.4 shows the effects of Gestational age, Babies gender, birth order, previous recurrent miscarriage (3 times

\begin{tabular}{|c|c|c|c|c|c|c|}
\hline \multirow{3}{*}{$\begin{array}{c}\text { Maternal } \\
\text { characteristics }\end{array}$} & \multirow{2}{*}{\multicolumn{4}{|c|}{$\begin{array}{c}\text { Infant birth weight group } \\
L B W(200) N B W(300)\end{array}$}} & \multirow{3}{*}{$\begin{array}{l}\text { Chi- } \\
\text { square }\end{array}$} & \multirow{3}{*}{$\begin{array}{c}P- \\
\text { value }\end{array}$} \\
\hline & & & & & & \\
\hline & no & $\%$ & no & $\%$ & & \\
\hline \multicolumn{7}{|c|}{ Gestational age* } \\
\hline$<37$ & 57 & $28.50 \%$ & 14 & $4.67 \%$ & \multirow{2}{*}{55.947} & \multirow{2}{*}{0} \\
\hline$>37$ & 143 & $71.50 \%$ & 286 & $95.33 \%$ & & \\
\hline \multicolumn{7}{|c|}{ Babies gender* } \\
\hline Male & 94 & $47 \%$ & 135 & $45 \%$ & \multirow{2}{*}{4.499} & \multirow{2}{*}{0.034} \\
\hline Female & 106 & $53 \%$ & 165 & $55 \%$ & & \\
\hline \multicolumn{7}{|c|}{ birth order } \\
\hline $1 \mathrm{st}$ & 86 & $43 \%$ & 115 & $38.33 \%$ & \multirow{4}{*}{3.092} & \multirow{4}{*}{0.378} \\
\hline 2nd -4 th & 86 & $43 \%$ & 125 & $41.67 \%$ & & \\
\hline 5 th -6 th & 21 & $10.50 \%$ & 45 & $15 \%$ & & \\
\hline More & 7 & $3.50 \%$ & 15 & $5 \%$ & & \\
\hline \multicolumn{7}{|c|}{ Previous recurrent miscarriage ( 3 times or more) } \\
\hline Yes & 41 & $20.50 \%$ & 42 & $14 \%$ & \multirow{2}{*}{2.763} & \multirow{2}{*}{0.096} \\
\hline No & 159 & $79.50 \%$ & 258 & $86 \%$ & & \\
\hline \multicolumn{7}{|c|}{ Previous history of LBW baby } \\
\hline Yes & 48 & $24 \%$ & 66 & $22 \%$ & \multirow{2}{*}{0.273} & \multirow{2}{*}{0.602} \\
\hline No & 152 & $76 \%$ & 234 & $78 \%$ & & \\
\hline
\end{tabular}




\section{International Journal of Science and Research (IJSR) \\ ISSN (Online): 2319-7064 \\ Index Copernicus Value (2013): 6.14 | Impact Factor (2015): 6.391}

\section{Discussion}

The aim of our study was to found out possible risk factors associated with LBW. Our study showed that $65 \%$ of the LBW group came from women age between 20-30 years although this is not statistically significant this age group now is common age group for marriage and may be most of these women had their first baby with little health education knowledge, other things we exclude any women with medical disease and as we know the age group abve 40 is the age of most medical diseases[12] from literature two studies suggested that maternal age was a risk factor for women who were older than 35 years or above $(14,15)$.

Our study also found that $57 \%$ of the cases had university degree education or higher although it was not statistically significant $(p=0.053)$, this may be duo to most of these university degree or higher women are working women and may had long period of standing [17]. Similar study done in Ohio which found that the women who had high school education or less the percentage of LBW was $11.13 \%$,for the women who had bachelor degree or higher education the percentage of LBW was $43.3 \%(\mathrm{P}<0.0001)$ [19]. Unlike study in Bangladesh which found that the women who didn't have any education at all, the percentage of LBW was $61.1 \%(\mathrm{P}<0.001)$, for the women who had primary or secondary education the percentage of LBW was $30.5 \%$ and for the women who had a collage degree or above the percentage of LBW was $8.3 \%(\mathrm{P}<0.001)$ [16] this may be related to the income which contribute so much in these countries.

In our study $49 \%$ of the cases are working mothers while in the control group $41 \%$ are working but this was not statistically significant. our explanation may be because working women usually stand and sit for long period and this may decrease the blood supply to fetus and so the fetus growth decrease which finally lead to LBW, the type of job as well as the working hours has role in why some women had and others not, most women here are teachers or nurses and the standing hours may be more $(12,17)$ Other study from Bangladesh found that $80.5 \%$ of the house wife had LBW while $19.5 \%$ of working mother had LBW [20], this may be explained by the higher income of the working women as they depend manly on women income and so they can feed them self with good nutrient and so good nutrient to the fetus.

In our study we found that the most of our study population had regular $\mathrm{ANC}, 86 \%$ of the cases have LBW in spite of the finding there is no significant relationship $(\mathrm{p}=0.338)$, this may be due to good antenatal care coverage in Hail region KSA as it is free and available even in remote areas. Regular antenatal care will prevent, detect and treat factors which negatively affect the baby also it provide advices and health education about food, supplementation and effect of smoking and alcohol [12], also small sample size of our study may had role in our result. Another study done in Oman, found that ANC visits significantly independent to the LBW [18], while two studies done in Bangladesh showed that there is a significant relationship between ANC visits and birth weight $(\mathrm{p}<0.001, \mathrm{OR}=29.386)(\mathrm{p}=0.001)(20$, 23). Our study assessed the use of supplementation during pregnancy and we found that $66.5 \%$ of the cases took their supplementation regularly while $70 \%$ of control did this means most of the study population has regular supplementation of iron, folic acid and calcium, this may be explained by their regular ANC but at the end there is no statistically significant relationship with LBW $(\mathrm{P}=$ 0.237).This may be explain by in our study we exclude babies with congenital anomalies as we know folic acid prevent congenital anomalies like neural tube defect $(12,20,21)$.We had two studies first one found that the risk of VLBW was decreased sevenfold with a $1^{\text {st }}$ trimester use and six fold when prenatal supplements were used in the $2^{\text {nd }}$ trimester [2],the other study in rural Gambia found that the use of prenatal supplements significantly increased birth weight, particularly during the nutritionally debilitating hungry season (June to October). Weight gain increased by $201 \mathrm{~g}(\mathrm{P}<0.001)$ in the hungry season, by $94 \mathrm{~g}(\mathrm{P}<0.01)$ in the harvest season (November to May), and by $136 \mathrm{~g}$ ( $\mathrm{P}<$ $0.001)$ over the whole year $[23,31]$.

Our study showed that $2 \%$ of the cases were active smoker while $1 \%$ of the control were, but this was not statistically significant $(p=0 \cdot 180)$ this may be due to small number of smoker women in our study (7 women). The effect of smoking during pregnancy was well studied as smoking will reduced placental perfusion leading to IUGR[12,25].It is estimated that a baby will weigh less than normal by the equation (15g multiple the number of cigarette per day)[12,24]. This result goes with a study done in Qatar regarding mother active smoking which found no significant association [27.On the other hand our study found that maternal exposure to passive smoking is significantly associated with LBW ( $\mathrm{p}=0 \cdot 000)$. This goes with a study done in Iraq to detect relation between passive smoking and LBW [27].

Regarding the relation between gestational age and LBW, our study found that $28.5 \%$ of the cases are $<37$ weeks while $4.6 \%$ of the control had. We found this relation was statistically significant $(\mathrm{P}=0.000)$, this goes with study done in South India found that there was significant association between gestational age and LBW [30] as preterm babies are usually small because they delivered prematurely and as gestation age advance the growth and weight of the fetus increase.

Also our study showed that being female is risk factor for LBW and this was statistically significant $(\mathrm{P}=0.034)$, this may be explained by most of women when they know the gender of the fetus is male they are more keen for antenatal visits and concern more about their nutrient [29], this goes with most of the literature such as south India study as they found in preterm babies the mean weight of the female was $1978 \mathrm{~g}$ and for male was were $2089 \mathrm{~g}$ [31]. Unlike study in India showed that the there is no association difference between gender and LBW (P-value >0.05) [32].

Regarding the birth order our study found most of the LBW are being the 1 st baby (43\%) but this does not reach the statistical significance level $(P=0.378)$, this may be explained by primgravida mothers may be have poor health education and her nutrient is deficient also first pregnancy associate with psychological disturbance which lead to her 


\section{International Journal of Science and Research (IJSR) \\ ISSN (Online): 2319-7064}

Index Copernicus Value (2013): 6.14 | Impact Factor (2015): 6.391

poor nutrient [33], other study in South India and in Malaysia found that there is association difference between baby order and $\operatorname{LBW}(30,32)$.

Regarding family monthly income our study showed that those family with low income $<3600$ SR had higher percentage of LBW $51.5 \%$ although this is not statistically significant this may be explained by the less income the less nutritional support the less socioeconomic status, this goes with study done in Bangladesh which found that women who had yearly income below average per person the percentage of LBW was $85.1 \%$.while women who had yearly income above average per person the percentage of LBW was $14.8 \%$ ( $p<0.001)[16]$.

Our study showed that women with Previous history of recurrent miscarriage (3 times or more) are less likely to have LBW (20.5\%) although this is not statistically significant. This may be because we exclude women with any medical disease like hypertension, anti-phospholipids syndrome which may contribute to LBW and recurrent miscarriage [12].Our study goes with study did in Bangladesh, which found that the women who haven't experienced any previous miscarriages the percentage of LBW was $35.1 \%$ and the women who had a previous miscarriages the percentage of LBW was $5.5 \%$, so the relation between abortion and LBW is statistically insignificant [16].

We studied the relation between women with previous history of LBW and LBW and we found that $76 \%$ of the cases had no previous history of LBW but this was statistically insignificant and may be due to our study exclusion criteria as above. In the same time other studies found that women who had a previous LBW baby, she has significantly higher risk of another LBW baby $(\mathrm{P}<0.05)$ [28,29].

\section{Conclusion}

\section{Based on these study findings}

- There is significant difference between case and control in term of passive smoking, gestational age, and baby's gender.

- There is no significant difference in maternal age, education, occupation, monthly income, ANC visits, and supplementation usage during pregnancy, active smoking, birth order, previous history of recurrent miscarriage, and previous history of LBW baby between two groups.

\section{Future Scope}

\section{Limitation}

Short study period

\section{Benefits}

From our research we know the most common factors which affect the birth weight in Hail region KSA.

\section{References}

[1] Cunningham L, Bloom H, Rouse S. Williams' obstetrics, 23 ed. New York, McGraw-Hill, 2010.

[2] Radhakrishnan T, Thankappan KR, Vasan RS, Sarma PS, Socioeconomic and demographic factors associated with birth weight. A community based study in Kerala, Indian Pediatrics, and 2000, 37: 872-876.

[3] Robert M. Kliegman, Bonita F. Stanton, Nina F. Schor, Joseph W. St. Geme III, Richard E. Behrman.Nelson Textbook ofPEDIATRICS19th edition. Elsevier Saunders 2011.

[4] UNDP Infants with low birth weight http://hdrstats.undp.org/indicators/67.html Accessed December 17, 2006.

[5] Koopd BL,Morgan L J and Battaglia FC,preventing of LBW institute of medicine Washinton1985

[6] Al-Essa YA, Ba Ageel HS,Haque KN.Low birth weight in Riyadh,Saudi Arabia the incidence and risk factors.Annal of tropical pediatrics 1991.11:75-82

[7] Muneera Al Husain, Lulu Al Naim, Ashry Gad and Osama K Zaki. Low birth weight: incidence and obstetric risk factors in Riyadh Saudi Arabia.

[8] Kramer MS, Determinants of low birth weight. Bulletin of the world health org 1987; 65[5]:663-737

[9] Giving Birth in Canada: the cost. Canadian Institute for Health Information. Canadian perinatal health report 2008

[10] Hack,M.,Weissman,B.,Breslau,N.,etal.Health of very low birth weight children during their first eight years journal of pediatrics1993;122:877-92.

[11] Kiely J, Yu S, Rowley D. Low birth weight and intrauterine growth retardation. Birth outcome.1998.

[12] Philip N Baker,Louise C Kenny.Obstetrics by Ten Teacher 19th edition 125-135 (2011 hodder \& ston hton ltd).

[13] Agueda A1, Ramón JM, Manau C, Guerrero A, Echeverría JJ. Periodontal disease as a risk factor for adverse pregnancy outcomes. J Clin Periodontal. 2008 Jan;35[1]:16-22. Epub 2007 Nov 21

[14] Hematram Yadav,Nagarajah Lee, Maternal Factors in Predicting Low Birth Weight Babies

[15]Lynda M. Colussi,Smoking during pregnancy: its effects on the prevalence of LBW infants, core scholar,6 - 2011

[16] Selina Khatun, Mahmudur Rahman,Socio-economic determinants of low birth weight in Bangladesh: A multivariate approach, Bangladesh Med Res Counc Bul,29-1- 2009.

[17] Keith T Palme,Effect of maternal work activity on preterm birth and low birth weight and pre eclampsia. Occupational and environmental medicine, 23 January 2011

[18] M. Islam, Mohamed Abdellatif, Khalid Al-Thihli, maternal and neonatal factors influencing preterm birth and low birth weight in oman, international journal of child health and nutrition, 2013, 2, 281-295.

[19] Selina Khatun \& Mahmudur Rahman, quality of antenatal care and its dose-response relationship with birth weight journal of biosocial science, volume 40,issue 03 may 2008, pp 321337.

[20] WilsonRD,DaviesG,DesilestsV,ReidG J.The use of folic acid for prevention of neural tube defect and other 


\section{International Journal of Science and Research (IJSR) \\ ISSN (Online): 2319-7064}

Index Copernicus Value (2013): 6.14 | Impact Factor (2015): 6.391

congenital anomalies.J-Obstet Gynaecol can.2003nov, 25[11]:959-73

[21]PitkinRM.Folate and reural tube defect.Amj Clin Nutr.2007 jan,85[1]:285s-288s

[22] Theresa O. Scholl1, Mary L. Hediger1, Adrianne Bendich2, Joan I. Schall1, Woollcott K. Smith3 And Paul M. Krueger1use of multivitamin/mineral prenatal supplements: influence on the outcome of pregnancy am j epidemiol vol, 146, no. 2, 1997 Med J Malaysia Vol 68 No 1 February 2013 maternal age- mothers with BMI

[23] SanaMCeesay, AndrewM Prentice, Timothy J Cole, Frances Foord, Elizabeth,M E Poskitt, Lawrence T Weaver, Roger $\mathrm{G}$, effects on birth weight and perinatal mortality of maternal dietary supplements in rural gambia, bmj volume 31527 September 1997.

[24] Stein, Z., Kline, J.). Smoking, alcohol and reproduction. American Journal of Public Health, (1983) 73[10], 1154-1156.

[25] Ananth, C, Savitz, D, \& Luther, E.Maternal cigarette smoking as a risk factor for placental abruption, placenta previa, and uterine bleeding in pregnancy. American Journal of Epidemiology, (1996). 144[9], 881-889.

[26] Abdulbari Bener,Najah Saleh, Khalil Salameh,Basma Basha, Sharen Joseph, Rama Al Buz Sociodemographic and consanguinity risk factors associated with low birth weight, J Pak Med Assoc. 2013 May;63[5]:598-603.

[27] M.A.A Wadi,S.S. Al-Sharbatti Relationship between birth weight and domestic maternal passive smoking exposure, East Mediterr Health J. 2011 Apr;17[4]:2906.

[28] J O. Awoleke.Maternal risk factors for low birth weight babies in Lagos, Nigeria. Arch Gynecol Obstet (2012) 285:1-6 DOI 10.1007/s00404-011-1885-y.21 January 2011.

[29] Mohammad K, Kassab M, Gamble J,Creedy DK and Foster J Factors associated with birth weight inequalities in Jordan,Int Nurs Rev. 2014 Sep;61[3]:435-40.

[30] Velusamy Saravana Kumar1, Lakshmanan Jeyaseelan1, Tunny Sebastian1, Annie Regi2, Jiji Mathew2 and Ruby Jose2.New birth weight reference standards customized to birth order and sex of babies from South India BMC Pregnancy Childbirth.2013 Feb $14 ; 13: 38$

[31] Swati Raje \& Shobha Rao maternal food consumption patterns and risk of low birth weight in rural maharashtra the indian journal of nutrition and dietetics, vol.52 [2], april - june 2015.

[32] Shyam V Ashtekar, Madhay B Kulkarni, Vaishalj S Sadavarte, and Rantan S Ashtekar Analysis of Birth Weights of a Rural Hospital.Indian J Community Med, 2010 Apr; 35[2]:252-255.

[33] Yadav H, Lee N.Maternal factors in predicting low birth weight babies. Med J Malaysia.2013; 68[1]:44-7.

[34] Swamy, G.K., et al. Maternal age, birth order, and race: differential effects on birth weight, Journal of Epidemiology Community Health, 66,136-142(2012). 